\title{
Embelin and Levodopa Combination Therapy Mitigates Parkinson's Disease Complications in Mice
}

\author{
Anand Koppal ${ }^{1}$, Senthilkumar Sivanesan ${ }^{2, \star}$, Vagdevi Hangarakatte Ramachandra ${ }^{1}$, Ethirajan \\ Sukumar',3, Rajagopalan Vijayaraghavan ${ }^{2}$
}

1Department of Pharmacology, Subbaiah Institute of Medical Sciences and Research Centre, Shivamogga, Karnataka, INDIA ${ }^{2}$ Department of Research and Development, Saveetha Institute of Medical and Technical Sciences, Chennai, Tamil Nadu, INDIA. ${ }^{3}$ Division of Ethnopharmacology and Phytochemistry, Entomology Research Institute, Loyola College, Chennai, Tamil Nadu, INDIA.

\begin{abstract}
Purpose: The present work evaluated the neuroprotective potential of embelin either alone and in combination with Levodopa in rotenone induced PD (Parkinson's disease) model mice. Methods: Swiss albino male adult mice were randomly divided into 7 groups. Group-1 (Control) received $2 \mathrm{~mL} / \mathrm{kg}$ olive oil by oral route (p.o.), Groups from 2 to 7 were induced with $2.5 \mathrm{mg} / \mathrm{kg}$ rotenone by intraperitoneal route (i.p.), levodopa was administered to Group-3. Group-4 and Group-5 were given $20 \mathrm{mg} / \mathrm{kg}$ and $40 \mathrm{mg} /$ $\mathrm{kg}$ embelin p.o. Group 6 and 7 were given embelin p.o. at dose of $20 \mathrm{mg}$ and $40 \mathrm{mg} /$ $\mathrm{kg}$ respectively and also $7.5 \mathrm{mg} / \mathrm{kg}$ Levodopa p.o. At the end of the experiment $\left(22^{\text {nd }}\right.$ day), blood was withdrawn by retro-orbital puncture to estimate various biochemical parameters and organs such as liver and brain, were dissected for histopathological and histochemical studies. Results: Drug treatment with a combination of embelin $(40 \mathrm{mg} /$ $\mathrm{kg})$ and levodopa $(7.5 \mathrm{mg} / \mathrm{kg})$ to PD mice showed better neuroprotective activity than the remaining drug treatment groups based on the results from biochemical, histopathology and $\alpha$-synuclein protein immunohistochemistry. Conclusion: The current in-vivo research showed that mice treated with embelin at a dose of $40 \mathrm{mg} / \mathrm{kg} \mathrm{b.w}$. along with reduced levodopa $(7.5 \mathrm{mg} / \mathrm{kg}$ ) standard therapy was effective to ameliorate rotenone induced PD complications.
\end{abstract}

Key words: Parkinson's disease, Swiss albino mice, Rotenone, Embelin, Levodopa.

\section{INTRODUCTION}

Parkinson's Disease (PD) is the second most chronic neurodegenerative disease of extrapyramidal motor functions affecting people worldwide next to Alzheimer's disease. Approximately $1 \%$ of people beyond 65 years of age are affected by PD with a prevalence rate more in men compared to women. ${ }^{1}$ Annual incidences are $0.2 / 1000$ with a prevalence of I.5/1000. Prevalence rates are similar throughout the world, except lower in West Africa and China. PD occurs due to progressive and selective damage and loss of dopaminergic neurons in the substantia nigra pars compacta (SNc) with depletion of dopamine neurotransmitter in brainstem regions and striatal projections. This disrupts the cerebral neuronal systems that are accountable particularly for motor activity and functions. ${ }^{2}$ PD symptoms include resting muscle tremors, slowed movement (bradykinesia), rigid muscles, impaired gait and balance and speech difficulties. Biochemical measurements and brain imaging studies suggest that at least $70 \%$ decrease in striatal dopamine levels before the onset of Parkinsonism and it progresses over time. ${ }^{3}$ Not all affected neurons in PD are dopaminergic. Non-motor symptoms are also commonly seen in PD. ${ }^{4}$ In PD, there is substantial cell loss in the substantia nigra region along with formation of Lewy bodies. ${ }^{5}$ Neither cell loss nor Lewy bodies is specific for PD and therefore both features are required for the PD diagnosis. Often PD is idiopathic, whereas other causes include
Submission Date: 19-05-2020; Revision Date: 24-12-2020; Accepted Date: 03-05-2021

DOI: 10.5530/ijper.55.2s.118 Correspondence:

Dr. Senthilkumar Sivanesan Department of Research and Development, Saveetha Institute of Medical and Technical Sciences, Chennai-600056, Tamil Nadu, INDIA.

Phone: +919566185430

Email id: senbio@gmail.com

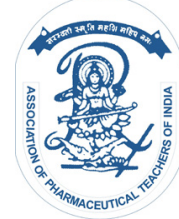

www.ijper.org 
severe head trauma, followed by stroke, viral infections, environmental toxins like chemicals and drug induced. While PD is still non-curable disorder, the standard levodopa therapy poses several side effects which include both motor and non-motor complications.

Rotenone selectively ablates the dopaminergic neurons in the nigrostriatal pathway in mice to develop Parkinsonism. The effects are similar to the behavioural manifestation and neurochemical mechanisms of PD in humans including mitochondrial dysfunction, apoptosis and oxidative stress. ${ }^{6}$ Exposure of mice to rotenone develops PD including selective nigrostriatal dopaminergic degeneration and- $\alpha$-synuclein-positive cytoplasmic inclusions. Findings from earlier studies have indicated that substantia nigra is one of the most affected brain regions of rotenone toxicity. ${ }^{7}$ This implicates higher susceptibility of neurons to free radical mediated damage. Histological findings in the midbrain revealed impaired motor coordination response and altered biochemical functions. ${ }^{8}$ This indicates that the midbrain area responds to oxidative stress caused by rotenone. The vulnerability of the midbrain to rotenoneinduced oxidative stress could also be seen from other works. ${ }^{9,10}$

Embelin, (2,5-dihydroxy-3-undecyl-1,4- benzoquinone) is an active constituent of the fruits of Embelia ribes Burm (Family: Myrsinaceae). Several works on embelin suggest many pharmacological actions rendered by this compound such as antioxidant, ${ }^{11}$ antidiabetic, ${ }^{12}$ antifertility, ${ }^{13}$ anti-bacterial, ${ }^{14}$ antitumor, analgesic and antiinflammatory. ${ }^{15}$ It exerts anti-inflammatory functions to relieve fever and rheumatism. Moreover, the protective effect of embelin on the CNS was shown in the form of anti-convulsant, ${ }^{16}$ anxiolytic, ${ }^{17}$ anti-Huntington's, ${ }^{18}$ and amelioration of hypoxia-ischemia induced neurological injury. ${ }^{19}$ The quinonoid compounds are ubiquitous in nature and implicated in numerous cellular functions through mechanisms of transfer of electron and hydrogen. Mice administered with embelin at 50 and $100 \mathrm{mg} / \mathrm{kg}$ oral dose showed no significant body weight change, mortality or apparent toxic effects confirming the safety of embelin. The $\mathrm{LD}_{50}$-value of embelin (i.p. route) was reported as $44 \mathrm{mg} / \mathrm{kg}$ and it was found that oral administration of embelin to mice and mice with doses up to $3 \mathrm{~g} / \mathrm{kg}$ did not show any toxic effects. ${ }^{20}$

Embelin crosses the blood-brain barrier to render protective effect in Central Nervous System. ${ }^{21}$ However studies are not available on the beneficial effect of embelin in rotenone induced PD models. Therefore, in the present study the neuroprotective efficacy of embelin was tested alone and in combination with levodopa in rotenone induced PD model mice.

\section{MATERIALS AND METHODS}

Experimental Animals: Adult male Swiss albino mice (25-30 g) of age between 8 and 12 weeks were procured from Biogen animal facility (Bengaluru, India). Animals were housed under standard laboratory conditions and maintained on a natural light/dark cycle with free access to food and water ad libitum. Before initiating the experiments, the animals were acclimatized for seven days to laboratory conditions.

Ethical Approval: The animal experimental protocol was approved by the Institutional Animal Ethics Committee SU/CLAR/RD/001/2017 and all animal procedures were performed as per the guidelines of the Committee for the Purpose of Control and Supervision of Experiments on Animals (CPCSEA), Government of India.

\section{Chemicals}

Rotenone was procured from TCI (Plau, USA) and olive oil from Thuruthel Drug Lines, (ERUMBA. Pharmacy Payyannur Kerala, India). FRAP (ferric reducing antioxidant power) was purchased from SD fine chemicals, India, TPTZ (2,4,6-Tri-(2-pyridyl)-5triazine) and Adrenaline were procured from Sigma Aldrich, India, anti-mouse alpha Synuclein primary antibody and biotinylated goat anti-mouse secondary antibody from Thermo Fisher Scientific, USA. Embelin was isolated as per the procedure in the Central Research Laboratory (CRL) facility of Department of Research and Development, Saveetha Institute of Medical and Technical Sciences, Chennai, India. Levodopa was obtained from SR Laboratories (Maharashtra, India) dimethyl sulfoxide (DMSO) from Pure Chemicals and hydroxypropyl cellulose (HPC) from HIMEDIA, (India). All the other chemicals and reagents used were of analytical grade.

\section{Preparation of rotenone and embelin}

Fifty $\mathrm{mg}$ rotenone was weighed and dissolved in $1 \mathrm{~mL}$ of DMSO. From this, an aliquot $0.2 \mathrm{~mL}$ was taken and diluted with $19.8 \mathrm{~mL}$ of olive oil to prepare a stock solution. Coarsely powdered berries of E. ribes were extracted with $\mathrm{n}$-hexane by cold extraction method (3x2L). After $72 \mathrm{hr}$, the solvent was decanted and distilled off over boiling water-bath. The extract so obtained was concentrated in vacuo and subjected to column chromatography over silica gel (100-200 mesh). 
Elution of the column with benzene yielded an orange powder which on crystallization with diethyl ether produced orange plates of embelin (Yield: $2 \mathrm{~g}$ ). ${ }^{22}$

\section{Experimental Design}

The mice were divided randomly into seven groups with six animals in each group. The grouping was done one day prior to the start of experiments. The duration of the experiment (injection and oral dosing) was 21 days. The tail of each mouse was marked with non-toxic permanent marker pen for identification. All the animals were weighed individually and the animal body weights were recorded. Group-1 (Control) received olive oil (2 $\mathrm{mL} / \mathrm{kg}$ ) by oral administration (p.o.) each day, Group-2 (PD) received $2.5 \mathrm{mg} / \mathrm{kg}$ rotenone by intraperitoneal route (i.p.) each day, Group-3 (PD + levodopa) received $7.5 \mathrm{mg} / \mathrm{kg}$ levodopa along with $2.5 \mathrm{mg} / \mathrm{kg}$ b.w (body weight) rotenone everyday by i.p. Group-4 (PD + embelin-20 mg/kg) and Group-5 (PD + embelin $40 \mathrm{mg} /$ $\mathrm{kg}$ ) by p.o. with $2.5 \mathrm{mg} / \mathrm{kg}$ rotenone by i.p. Group-6 (PD + embelin-20 mg/kg + levodopa) and Group-7 (PD + embelin $40 \mathrm{mg} / \mathrm{kg}$ + levodopa) received embelin and $7.5 \mathrm{mg} / \mathrm{kg}$ levodopa p.o. along with $2.5 \mathrm{mg} / \mathrm{kg}$ rotenone i.p. At the end of the experiment (day 22), the animals were anaesthetized using isoflurane for blood collection $(0.25 \mathrm{~mL})$ by retro-orbital plexus. Serum biochemical parameters such as triiodothyronine (T3), thyroid stimulating hormone (TSH), total antioxidant capacity (TAC) and superoxide dismutase (SOD) were performed. Brain and liver tissues were dissected out carefully and used for histology and immunohistochemical studies.

Estimation of serum T3 and TSH levels: Blood collected in vacutainer tube (clot activator) was allowed to clot at room temperature for $20 \mathrm{~min}$. To prepare serum, clotted blood was centrifuged at $3000 \mathrm{rpm}$ for $10 \mathrm{~min}$ at $4^{\circ} \mathrm{C}$ and separated serum was used for further analysis. The amount of serum used for measuring thyroid stimulating hormone (TSH) and Triiodothyronine (T3) was $150 \mu \mathrm{L}^{23,24}$ The levels of T3 and TSH were measured by ELISA kit according to the BIOBASE manufacturer kits instructions using IMMULITE 2000 immunoassay system (Siemens Healthcare Diagnostics Chennai India).

Super oxide dismutase (SOD) assay: Tubes containing $0.5 \mathrm{~mL}$ of sample was made up to $2.5 \mathrm{~mL}$ using buffer solution $(0.5 \mathrm{~mL}$ of $0.6 \mathrm{mM}$ EDTA solution, $0.5 \mathrm{~mL}$ of $300 \mathrm{mM}$ carbonate buffer) The reaction was started by adding of $0.4 \mathrm{~mL}$ of $1.8 \mathrm{mM}$ adrenaline and the increase in absorbance at $480 \mathrm{~nm}$ was measured using UV spectrophotometer. $50 \%$ autoxidation of adrenaline to adrenochrome was performed in a control tube without the enzyme. The enzyme activity is expressed as units/ $\mathrm{min} / \mathrm{mg}$ protein. ${ }^{25}$

Estimation of total antioxidant capacity (TAC): Serum TAC was measured following the method of Benzie and Strain. ${ }^{26} \mathrm{~A}$ working solution of FRAP was prepared by adding $10 \mathrm{mM}$ of 2,4,6-Tripyridyl-S-triazine (TPTZ) solution in $40 \mathrm{M} \mathrm{HCl}, 0.02 \mathrm{M} \mathrm{FeCl}_{3}$ and acetate buffer pH3.6 was added and mixed. This was followed by the addition of $8 \mu \mathrm{L}$ of serum and $240 \mu \mathrm{L}$ of FRAP reagent. The mixture was incubated for $10 \mathrm{~min}$ at room temperature and the absorbance was measured at 593 $\mathrm{nm}$. TAC is expressed as $\mathrm{mmol} / \mathrm{L}$.

Alpha synuclein immunohistochemistry and histopathology: Immunohistochemical analysis was done to assess PD marker by performing alpha-synuclein staining in brain tissues. Tissues were immersed in the fixative solution for $4 \mathrm{hr}$. The tissues were cryoprotected in $30 \%$ sucrose, embedded in tissue-freezing medium with liquid nitrogen and cut into frozen sections (3-5 $\mu \mathrm{m})$ using a cryostat. Sections were stored in anti-freeze buffer. Parallel free-floating sections were subjected to endogenous peroxidase quenched with $1 \% \mathrm{H}_{2} \mathrm{O}_{2}$ in PBS, followed by treatment with blocking buffer (5\% normal chicken serum in PBS and $0.3 \%$ Triton $\mathrm{X}-100$ for overnight at $4^{\circ} \mathrm{C}$ ) and incubated with alphasynuclein primary antibody (1:100). After washing with PBS, tissues were incubated with a biotinylated goat anti-mouse secondary antibody (1:400). The tissues were subsequently exposed to an avidin-biotin peroxidase complex for $2 \mathrm{hr}$. The peroxidase activity was visualized using a stable diaminobenzidine. A small piece of the brain and liver tissue was fixed with $10 \%$ neutral buffered formalin, embedded in paraffin wax and cut into sections of $5-\mu \mathrm{m}$ thickness. The sections were stained with haematoxylin and eosin for histopathological observations.

\section{Statistical Analysis}

Results are expressed as mean \pm SEM. One Way ANOVA followed by Bonferroni multiple comparison posthoc test was used for comparison between the groups. $P<0.05$ was considered as statistically significant. Sigma plot 13 (Systat, USA) was used for statistical analysis.

\section{RESULTS}

\section{Analysis of serum TAC and SOD levels}

The mean and SE of TAC $(\mathrm{mmol} / \mathrm{L})$ in groups 1 to 7 were $624.7 \pm 4.9,89.6 \pm 1.1,431.1 \pm 2.5,116.7 \pm 2.1,218.9$ $\pm 1.0,328.2 \pm 1.1$ and $541.3 \pm 4.9$ respectively. The mean and SE of SOD $(\mu \mathrm{g} / \mathrm{dL})$ in groups 1 to 7 were $92.6 \pm 0.5$, $8.5 \pm 0.3,48.5 \pm 0.4,14.8 \pm 0.3,31.8 \pm 0.2,55.7 \pm 0.2$ and 
$76.0 \pm 0.5$ respectively (Table 1$)$. There was significant $(p<0.05)$ mean difference of TAC and SOD levels between the groups (Figure 1). The combination drug treatment showed significant improvement in the TAC and SOD levels. Group 2 (PD) mice showed 85.7 and $90.8 \%$ decrease in TAC and SOD levels respectively in comparison with control whereas Group 7 subjected to treatment with a combination of embelin $(40 \mathrm{mg} /$ $\mathrm{kg})$ and Levodopa $(7.5 \mathrm{mg} / \mathrm{kg})$ along with rotenone $(2.5$ $\mathrm{mg} / \mathrm{kg}$ ) showed only 13.4 and $18 \%$ decrease respectively of those enzyme activities in comparison with control.

\section{Analysis of serum T3 and TSH alterations}

The reference value of Total T3 and TSH in normal mouse ranges from $0.08-0.18 \mu \mathrm{g} / \mathrm{dL}$ and $0.85-6.0 \mu \mathrm{g} /$ $\mathrm{dL}$ respectively. The mean and SE of T3 (ng/dL) for the 1 to 7 groups were $180.6 \pm 1.7,48.4 \pm 1.4,116.7 \pm 2.5$, $65.0 \pm 1.6,90.6 \pm 1.3,130.2 \pm 2.4$ and $153.6 \pm 3.4$ respectively (Figure 2, Table 2). The mean and SE of TSH ( $\mu \mathrm{g} /$ $\mathrm{dL})$ for the 1 to 7 groups were $1.59 \pm 0.2,18.96 \pm 0.40$, $6.29 \pm 0.1,13.50 \pm 0.3,9.41 \pm 0.1,5.67 \pm 0.1$ and $3.54 \pm 0.2$ respectively ((Figure 2, Table 2). Group 2 (PD) mice showed 3.73-fold decrease in T3 as compared to control (group 1), whereas group 7 subjected to treatment with a combination of embelin $(40 \mathrm{mg} / \mathrm{kg})$ and Levodopa along with rotenone showed only 1.2-fold decrease in T3 in comparison with control. For TSH levels, PD mice (group 2) mice showed 11.9-fold increase as compared with control (group 1), whereas group 7 mice subjected to treatment with a combination of embelin $(40 \mathrm{mg} / \mathrm{kg})$ and levodopa along with rotenone showed only 2.2 -fold increase in comparison with control. While the levels

\begin{tabular}{|c|c|c|}
\hline Group & $\begin{array}{c}\text { Total anti- } \\
\text { oxidant capacity } \\
\text { (mmol/L) }\end{array}$ & $\begin{array}{l}\text { Superoxide } \\
\text { dismutase } \\
(\mu \mathrm{mol} / \mathrm{mL})\end{array}$ \\
\hline Control & $624.7 \pm 4.9$ & $92.6 \pm 0.5$ \\
\hline Rotenone & $89.6 \pm 1.1^{* * *}$ & $8.5 \pm 0.3^{* * *}$ \\
\hline Rotenone + Levodopa & $431.1 \pm 2.47^{* * *}$ & $48.5 \pm 0.4^{* * *}$ \\
\hline Embelin low dose & $116.7 \pm 2.1^{* * * *}$ & $14.8 \pm 0.3^{t+* t}$ \\
\hline Embelin high dose & $218.9 \pm 1.0^{*+* t}$ & $31.8 \pm 0.2^{* * *}$ \\
\hline $\begin{array}{l}\text { Embelin low dose+ } \\
\text { Levodopa }\end{array}$ & $328.2 \pm 1.1^{* * * *}$ & $55.7 \pm 0.24^{* * *}$ \\
\hline $\begin{array}{c}\text { Embelin high dose+ } \\
\text { Levodopa }\end{array}$ & $541.3 \pm 4.9^{* * * t}$ & $76.0 \pm 0.5^{* * *}$ \\
\hline
\end{tabular}

of T3 and TSH from control group were within the reference range, PD group showed significantly $(p<0.05)$ altered T3 and TSH levels than the control group. However, treatment with various doses of Embelin either alone or in combination with Levodopa to PD mice significantly altered those values. The PD induced decrease in T3 levels were found reversed in Embelin plus Levodopa treatment groups and was statistically significant in comparison with PD group or Embelin

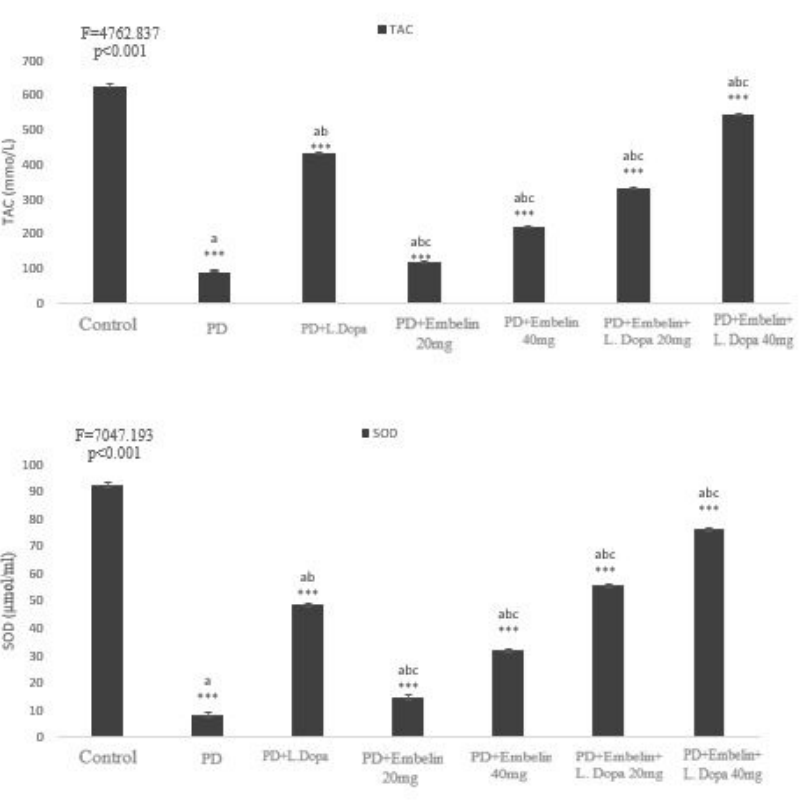

Figure 1: Protective effect of embelin on rotenone induced changes in TAC and SOD. A Significantly different from control group. B Significantly different from rotenone group. C Significantly different from rotenone+L-Dopa group. Values are mean \pm SE ( $n=6$ each).

\section{Table 2: Protective effect of Embelin on rotenone induced changes in tri-iodothyronine}

(T3) and thyroid stimulating hormone (TSH). Values are mean + SE ( $n=6$ each).

\begin{tabular}{|c|c|c|}
\hline Group & $\begin{array}{c}\text { Triiodothyronine (T3) } \\
\text { (ng/dL) }\end{array}$ & $\begin{array}{c}\text { Thyroid } \\
\text { Stimulating } \\
\text { Hormone (TSH) } \\
\text { ( } \mu \text { g/dL) }\end{array}$ \\
\hline Control & $180.62 \pm 1.73$ & $1.59 \pm 0.15$ \\
\hline Rotenone & $48.48 \pm 1.44^{* * *}$ & $18.96 \pm 0.40^{* * *}$ \\
\hline Rotenone + & $116.7 \pm 2.52^{* * *}$ & $6.29 \pm 0.12^{* * *}$ \\
\hline $\begin{array}{c}\text { Embelin low dose } \\
\text { Embelin high dose }\end{array}$ & $65.00 \pm 1.52^{* *}$ & $13.50 \pm 0.31^{* * *}$ \\
\hline $\begin{array}{c}\text { Embelin low dose+ } \\
\text { Levodopa }\end{array}$ & $130.28 \pm 2.51^{* * *}$ & $9.41 \pm 0.10^{* * *}$ \\
\hline $\begin{array}{c}\text { Embelin high dose+ } \\
\text { Levodopa }\end{array}$ & $153.62 \pm 3.35^{* * *}$ & $3.54 \pm 0.16^{* * *}$ \\
\hline
\end{tabular}


alone treated groups. On the other hand, the PD induced elevation of TSH content were found to be significantly decreased in Embelin plus Levodopa treatment groups as compared with PD group or Embelin alone treated groups. While several works depict normal values of TSH in PD patients, the present result obtained from mice is a bit contrasting. Since we lack studies on TSH assessment from PD mouse models, further detailed exploration is required.

\section{Immunostaining of alpha-synuclein in substantia niagra region}

The immunoreactivity for alpha-synuclein was predominantly present in damaged brain cells and exhibited a positive reaction. In PD mice brains, the intensity of alpha synuclein (Figure 3A, Slide B) was significantly higher as compared to control group brains (Figure 3A, Slide A). In Embelin treated groups, the alpha-synuclein expression levels were markedly decreased. While the expression of this protein was found to be decreased in the brain samples of Levodopa treatment group (Figure 3A, Slide C), Embelin (20mg/ $\mathrm{kg}$ ) group (Figure 3A, Slide D) and Embelin (40mg/ $\mathrm{kg}$ ) group (Figure 3A, Slide E), very low (mild positive) expression was seen in combination treatment groups Embelin $(20 \mathrm{mg} / \mathrm{kg})+$ Levodopa (Figure 3A, Slide F) Embelin $(40 \mathrm{mg} / \mathrm{kg})+$ Levodopa (Figure $3 \mathrm{~A}$, Slide G). Alpha synuclein expression in all the groups has been analysed. Results were expressed as mean \pm SEM $(n$

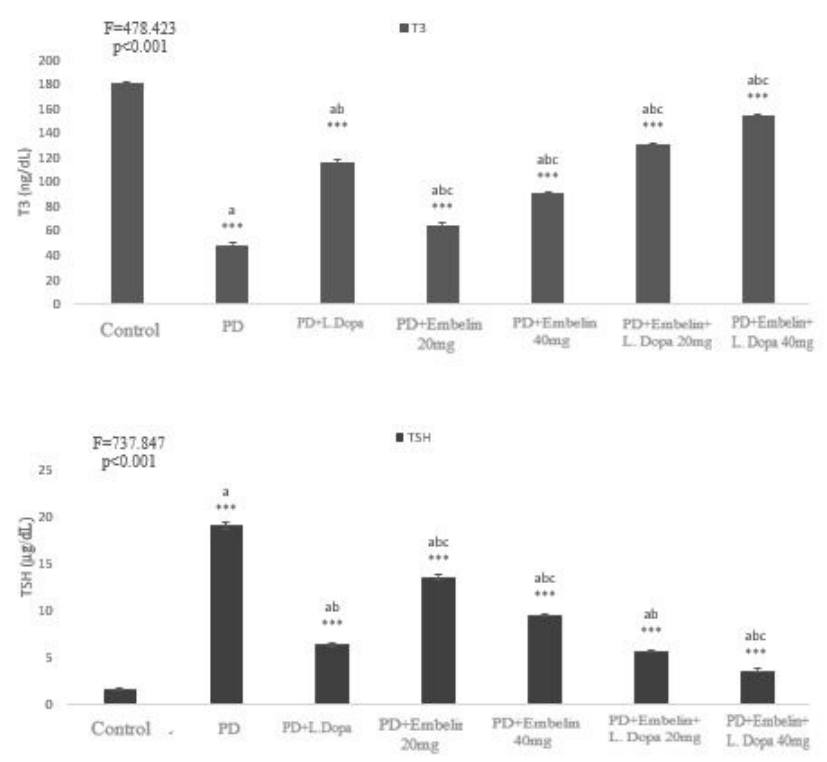

Figure 2: Protective effect of embelin on rotenone induced changes in T3 and TSH aSignificantly different from control group. bSignificantly different from rotenone group.

cSignificantly different from rotenone+L-Dopa group. Values are mean $\pm \operatorname{SE}(n=6$ each).
$=4)$ and shown statistically significant compared with rotenone group. (Figure 3B)

\section{Brain and liver histopathology alterations}

The histological changes observed in the brain and liver tissues of various groups are depicted in Figure 4 and 5 respectively. Control brain tissue (Figure 4, Slide A) revealed the presence of normal neuronal cells with prominent nucleus (small arrow), cytoplasm and normal striatum architectural formation. Based on the observations made from the brain tissue of rotenone group (Figure 4, Slide B), there was more evidence of pyknotic nuclei (arrow mark), Lewy bodies (LB), necrosis and neuronal degeneration with decreased number of neurons and cytoplasmic shrinkage. Levodopa group

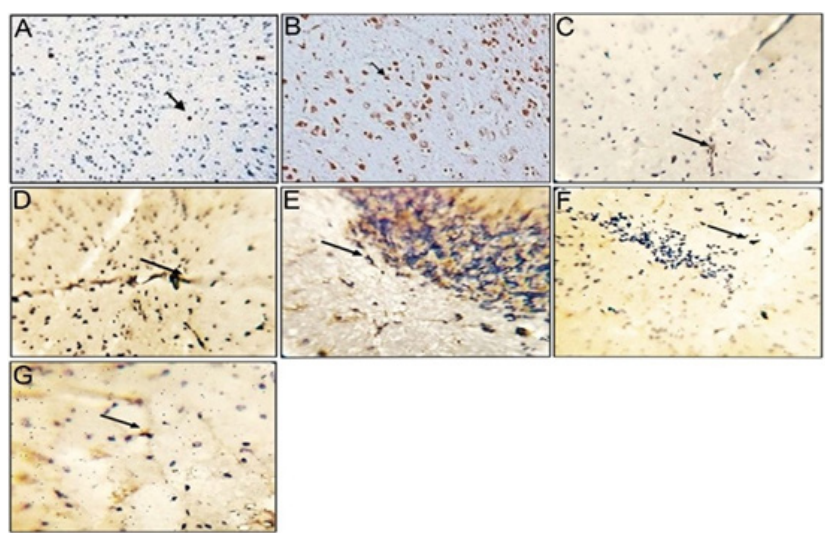

Figure 3A: Immunostaining of Alpha-synuclein in mid-brain region of mice. Magnification (40x). Slide A - Control, Slide B PD, Slide C- PD + L-DOPA (7.5 mg/kg), Slide D - PD + embelin $(20 \mathrm{mg} / \mathrm{kg})$, Slide E- PD + embelin (40 mg/kg), Slide F- PD

+ Embelin (20 mg/kg) + L-DOPA (7.5 mg/kg), Slide G - PD + Embelin $(40 \mathrm{mg} / \mathrm{kg})+$ L-DOPA $(7.5 \mathrm{mg} / \mathrm{kg})$.

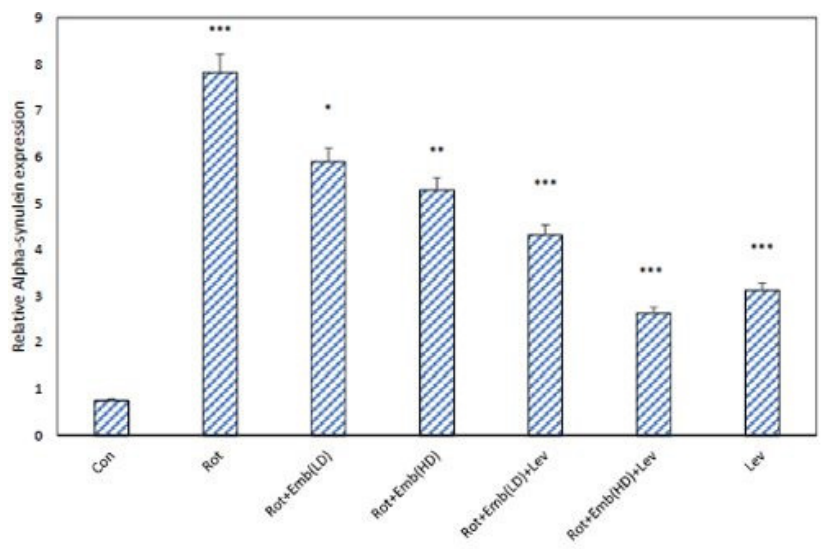

Figure 3B: Representative bar graph showing the quantification of Alpha Synuclein Expression in various groups: Results were expressed as mean $\pm \operatorname{SEM}(n=3)$. ${ }^{* * *} p<0.001$ statistically significant as compared with Control, whereas the other treated groups showed ${ }^{*} p<0.05$; ${ }^{* *} p<0.01$; ${ }^{* * *} p<0.001$ statistically significant as compared with rotenone induced group. 
(Figure 4, Slide C) showed less evidence of pyknotic nuclei (arrow mark). Rotenone + embelin (20mg/ $\mathrm{kg}$ ) group (Figure 4, Slide D) indicated less evidence of pyknotic nuclei (arrow mark), LB and neuronal degeneration. In rotenone+ embelin $(40 \mathrm{mg} / \mathrm{kg})$ group (Figure 4, Slide E) the pyknotic nuclei and LB was less noticed with moderate evidence of normal neurons and less inflammation $(20 \mathrm{mg} / \mathrm{kg})+$ embelin $(20 \mathrm{mg} / \mathrm{kg})+$ Levodopa group (Figure 4, Slide F) very less brain tissue inflammation was seen with distinct boundaries and a greater number of prominent nuclei neurons indicating less brain tissue damage. Rotenone + embelin $(40 \mathrm{mg} / \mathrm{kg})$ + Levodopa group (Figure 4, Slide G) showed optimal sized cells with well-defined nucleus (black arrow) and less neuronal infiltration (red arrow) indicating less brain tissue. Light microscopic examination of haematoxylin and eosin-stained liver sections of group 1 (Figure 5, Slide A) indicated the presence of normal hepatic cells with well-preserved cytoplasm, prominent nucleus and normal architectural formation. It was observed that in group 2 mice induced only with rotenone (Figure 5 , Slide B), there was single cell necrosis (triangle head) and occasional focal widening of the perivenous centrilobular spaces (broad arrow) suggestive of loss of centrilobular hepatocytes. In group 3 mice subjected to Levodopa treatment (Figure 5, Slide C), slight diffuse cytoplasmic hepatocellular vacuolation (small arrow) was seen. Liver tissues of group 4 mice subjected to embelin $(20 \mathrm{mg} / \mathrm{kg})$ treatment (Figure 5, Slide D), shown less diffuse of cytoplasmic hepatocellular vacuolation (small arrow) and infrequent focal widespread of the perivenous centrilobular spaces. Group 5 mice which received embelin $(40 \mathrm{mg} / \mathrm{kg}$ ) (Figure 5 , Slide E) shown severe thinning of hepatic cords due to hepato cellular atrophy and slightly damaged hepatic nucleoli. Mild

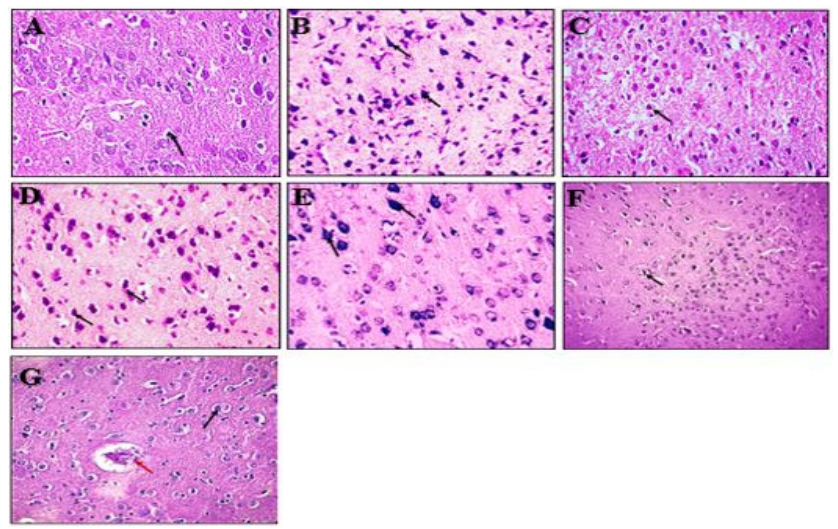

Figure 4: Histology of H\&E stained brain tissues. Slide A Control, Slide B - PD, Slide C- PD + L-DOPA (7.5 mg/kg), Slide D - PD + embelin (20 mg/kg), Slide E- PD + embelin (40 mg/kg), Slide F- PD + Embelin $(20 \mathrm{mg} / \mathrm{kg})+\mathrm{L}-$ DOPA $(7.5 \mathrm{mg} / \mathrm{kg})$, Slide G - PD + Embelin (40 mg/kg) + L-DOPA (7.5 mg/kg). inflammation was noted at the central vein (long arrow). Group 6 mice which received $(20 \mathrm{mg} / \mathrm{kg})$ embelin and Levodopa therapy (Figure 5, Slide F), less hepatocytes degeneration was seen with presence of blood sinusoids. Group 7 mice which received $(40 \mathrm{mg} / \mathrm{kg}$ ) embelin and Levodopa (Figure 5, Slide G) showed regeneration of hepatocyte was seen with very much reduced hepatic atrophy (small arrow).

\section{DISCUSSION}

The drugs which are currently used to treat PD patients pose several adverse effects and consequences following long term treatment. Chronic use of Levodopa is associated with dyskinesia in more than $50 \%$ of patients. Treatment with Levodopa affects tryptophan metabolism through the kynurenine pathway. ${ }^{27}$ Therefore new interventional approaches are required to overcome several adverse complications of PD in the present scenario. As plant extract-based compounds are generally safer than synthetic compounds apart from their therapeutic value, they could be promising for the treatment of neurological disorders including $\mathrm{PD}^{28,29}$ In the present study, embelin was tested alone and in combination with Levodopa to explore its neuroprotective functions in rotenone-induced PD mice. Rotenone is a precise inhibitor of mitochondrial complex I to provoke oxidative stress-mediated neuropathology ${ }^{30-32}$ and hence considered as a model of PD. ${ }^{33}$ Rotenone induces the degeneration of the nigrostriatal dopaminergic pathway which is one of the main pathological hallmarks of $\mathrm{PD} .^{32}$ Prolonged Levodopa therapy for PD causes problems which include depression, sleep disturbance and dyskinesia. ${ }^{31}$ Combination of levodopa with other drugs to increase

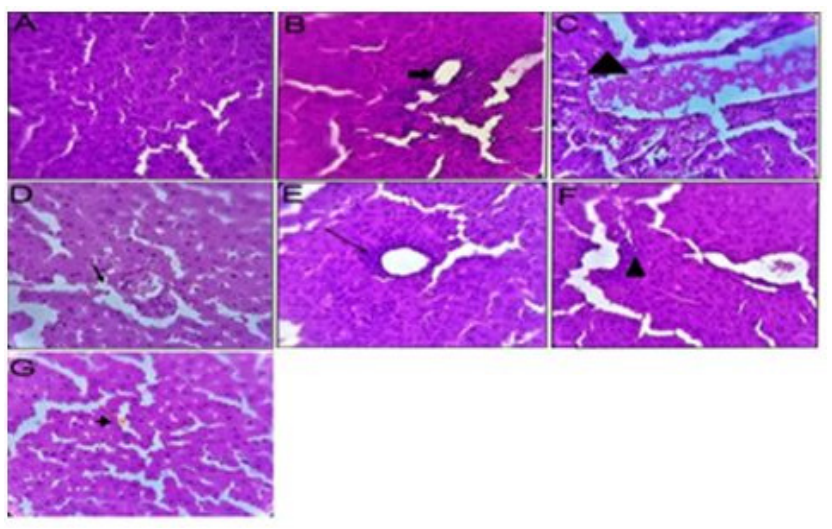

Figure 5: Histology of H\&Estained liver tissues. Slide A Control, Slide B - PD, Slide C- PD + L-DOPA (7.5 mg/kg), Slide D - PD + embelin (20 mg/kg), Slide E- PD + embelin (40 mg/kg), Slide F- PD + Embelin (20 mg/kg) + L-DOPA (7.5 mg/kg), Slide $\mathrm{G}$ - PD + Embelin (40 mg/kg) + L-DOPA (7.5 mg/kg). 
the bio-availability is an alternative. ${ }^{29}$ Earlier research found that Levodopa may be neurotoxic which endorse the degeneration of nigrostriatal projections. ${ }^{34}$ In addition, prolonged Levodopa treatment correlates with intracellular accumulation of oxidative stress. ${ }^{35}$ To overcome these problems, the field of herbal medicine has focused on natural products to minimize the side effects.

The present work explored the neuroprotective efficacy of orally administered embelin drug tested alone and in combination with Levodopa in PD model mice. The findings suggest that embelin when administered either alone and in combination with Levodopa therapy significantly reduced the $\alpha$-synuclein pathology as well as protected midbrain cells through antioxidant mechanisms. However, better effect was seen with embelin and Levodopa $(7.5 \mathrm{mg} / \mathrm{kg})$ combination treatment rather than embelin alone treatments. The antioxidant role of embelin in PD was also evaluated through estimation of SOD and TAC levels. Moreover, the present work revealed how embelin treatment altered serum T3 and TSH levels to reduce thyroid complications in PD. Recent in vitro studies have shown that embelin reversed MPTP toxicity by promoting mitochondrial biogenesis through elevation of pAMPK, SIRT1 and PGC1 $\alpha$ markers. ${ }^{36}$ In addition to this, increased NAD/ $\mathrm{NADH}$ levels were also attributed to protective effect of embelin involving mitochondrial uncoupling effects. Therefore, the present study adds impetus to earlier in vitro work thereby suggesting the therapeutic efficacy of embelin in animal model of PD. Using MPTP mouse model of PD it was shown that embelin $(10 \mathrm{mg} / \mathrm{kg})$ could mitigate MPTP-induced loss of TH staining and altered striatal dopamine levels apart from influencing the markers of mitochondrial biogenesis pathway. ${ }^{36}$ The same group proved the protective role of embelin against MPTP by in vitro studies involving N27 dopaminergic cells.

It has been established that the dopaminergic neurons in PD exist in a state of constant oxidative stress. ${ }^{37}$ Decreased TAC and SOD levels in PD implicate elevated levels of reactive oxygen species. This is in agreement with other studies which suggest that oxidative damage is involved in the neuronal abnormalities in PD. ${ }^{38}$ However, treatment with embelin or levodopa or a combination of embelin and levodopa increased the levels of TAC and SOD. Complex-I of the mitochondrial respiratory chain is a major source of superoxide free radicals. The enzyme activity of SOD is altered due to oxidative stress in rotenone treated animals. ${ }^{39}$ Decreased SOD activity would be detrimental in cases when superoxide radical production is increased. The decrease in SOD activity following rotenone treatment might be due to inactivation of SOD by ROS. ${ }^{40}$ Such low levels have also been detected in SNpc neurons of PD patients as compared to healthy idividuals. ${ }^{41}$ In the present study SOD and TAC levels were lower in rotenone treated animals. Studies have shown that decreased levels of TAC and SOD might cause oxidative damage to DNA, protein and lipids in neurodegenerative disease. ${ }^{42,43}$ Decreased levels of SOD and TAC might play an important role in induction of oxidative stress in brain. ${ }^{44}$ Oxidative stress, as well as stress triggered by hydroxyl radicals, is one of the key features of $\mathrm{PD}$ pathogenesis. The reduced levels of TAC in PD group were significantly reversed in embelin treated groups as well as embelin + levodopa combination groups $(p<0.001)$. However, the effect was more pronounced in embelin + levodopa combination treatment groups, the maximum effect seen at Embelin $40 \mathrm{mg} / \mathrm{kg}$ dose. Previous work showed that how embelin enhanced antioxidant and suppressed lipid peroxidation in carbon tetrachlorideinduced free radical production and liver toxicity. ${ }^{45}$ It scavenged DPPH radicals to prevent deoxyribose degradation induced by hydroxyl radicals. Also, embelin has considerably shown inhibition of lipid peroxidation and up-regulation of Mn-superoxide dismutase levels. ${ }^{46}$ In earlier work Umehara et al. ${ }^{47}$ reported significantly lower levels of T3 in PD patients with notable motor symptoms which could be associated with the present findings. However, there is a limited information available from patients with aggravated parkinsonism due to hypothyroidism. ${ }^{48,49}$ It is accepted worldwide that thyroid role has great influence on cognition. Functions of the hypothalamic-pituitary-thyroid (HPT) axis have been revealed to undergo many changes as age increases. ${ }^{50}$ Due to the connecting link between dopaminergic system and hypothalamic-pituitary-thyroid axis, impaired TSH and thyroid hormone (TH) levels are associated with PD severity and complications and the drug of choice for PD such as levodopa also impact the hypothalamicpituitary-thyroid axis. ${ }^{51}$ Even though there are still many debates regarding the connection between thyroid function and neurodegenerative disease, it seems that the free T3 levels were found to be lower in PD patients particularly with akinetic-rigid motor subtype, whereas TSH levels were lesser in patients with tremor-dominant type or mixed type, signifying a relation of the thyroid hormone level with PD motor signs. ${ }^{47}$ Unfortunately we lack convincing studies from PD mice on TSH levels. 
But, in support of our findings, it is evident from a recent human study that the TSH index in the early PD group is significantly higher than that seen in advanced group. ${ }^{52}$ As tremors are rarely noticeable in rotenone induced PD models, ${ }^{53}$ the fact that increased TSH levels seen in the present results may be justified owing to the fact the hyperthyroid dysfunctions are manifested with tremor dominant type. ${ }^{54}$ Another study reported that hypothyroidism was not more prevalent in PD subjects but owing to the fact that there was considerable overlap of symptoms and signs they suggested assessment of thyroid function in patients could be convincing to see the worsening of PD symptoms. ${ }^{55}$ It is also notifying feature that enhanced tremor occurs in hyperthyroid state of PD. ${ }^{56}$ Unfortunately, we lack studies on how Levodopa/embelin treatment could restore thyroid parameters in PD condition and hence further studies are required to explore the detailed mechanistic insights. Therefore, a more detailed study of TSH assessment in animal models of PD is also required to further validate these findings. Although our previous works explored various biochemical and molecular parameters to assess PD pathology in rodents using both i.p and oral modes of rotenone induction, ${ }^{57-59}$ testing the therapeutic value of herbal drugs in animal models has witnessed considerable growth in many recent research works. ${ }^{60-62}$

\section{CONCLUSION}

The present study finding depicts that administration of rotenone in Swiss Albino mice decreased TAC and SOD implicating impaired anti-oxidant status, accompanied by brain and liver histological changes in PD condition. Treatment with embelin alone $(40 \mathrm{mg} /$ $\mathrm{kg}$ ) and a combination of Embelin $40 \mathrm{mg} / \mathrm{kg}$ dose with Levodopa $7.5 \mathrm{mg} / \mathrm{kg}$ ameliorated peripheral oxidative stress, thyroid hormone changes, brain alpha synuclein expression as well as brain and liver tissue damage in PD mice implicating the therapeutic efficacy of embelin as well as embelin plus levodopa therapy.

\section{ACKNOWLEDGEMENT}

We thank Dr. S. Ganesh, Scientist EII, Organic Lab, Central Leather Research Institute, Chennai, India for providing his support for FTIR characterization of Embelin. We also thank S. Madhankumar and S. Praveenkumar, Lab for providing their assistance during animal experiments.

\section{CONFLICT OF INTEREST}

The authors declare that they have no conflict of interest.

\section{ABBREVIATIONS}

CNS: Central Nervous System; DMSO: Dimethyl sulfoxide; DN: Dopaminergic neurons; DNA: Deoxyribonucleic acid; HPT: Hypothalamic-pituitarythyroid; PD: Parkinson's disease; ROS: Reactive oxygen species; SOD: Superoxide dismutase; T3: Triiodothyronine; TAC: Total antioxidant capacity; TSH: Thyroid stimulating hormone; L-Dopa: Levodopa.

\section{REFERENCES}

1. Dluzen DE, McDermott JL. Gender differences in neurotoxicity of the nigrostriatal dopaminergic system: Implications for Parkinson's disease. The Journal of Gender-Specific Medicine: JGSM: The Official Journal of the Partnership for Women's Health at Columbia. 2000;3(6):36-42.

2. Dawson TM, Dawson VL. Molecular pathways of neurodegeneration in Parkinson's disease. Science. 2003;302(5646):819-22.

3. Brooks DJ. The early diagnosis of Parkinson's disease. Annals of Neurology. 1998;44(S 11):S10-8.

4. Langston JW. The Parkinson's complex: Parkinsonism is just the tip of the iceberg. Annals of Neurology: Official Journal of the American Neurological Association and the Child Neurology Society. 2006;59(4):591-6.

5. Postuma RB, Berg D, Adler CH, Bloem BR, Chan P, Deuschl G, et al. The new definition and diagnostic criteria of Parkinson's disease. The Lancet Neurology. 2016;15(6):546-8.

6. Fahn S, Sulzer D. Neurodegeneration and neuroprotection in Parkinson disease. Neuro Rx. 2004;1(1):139-54

7. Testa CM, Sherer TB, Greenamyre JT. Rotenone induces oxidative stress and dopaminergic neuron damage in organotypic substantia nigra cultures. Molecular Brain Research. 2005;134(1):109-18.

8. Valko M, Leibfritz D, Moncol J, Cronin MT, Mazur M, Telser J. Free radicals and antioxidants in normal physiological functions and human disease. The International Journal of Biochemistry and Cell Biology. 2007;39(1):44-84.

9. Chen $\mathrm{Y}, \mathrm{Hou} \mathrm{Y}, \mathrm{Ge} \mathrm{R}, \mathrm{Han} \mathrm{J}, \mathrm{Xu} \mathrm{J}$, Chen J, et al. Protective effect of roscovitine against rotenone-induced parkinsonism. Restor Neurol Neurosci. 2018;36(5):629-38.

10. Mbiydzenyuy NE, Ninsiima HI, Valladares MB, Pieme CA. Zinc and linoleic acid pre-treatment attenuates biochemical and histological changes in the midbrain of rats with rotenone-induced Parkinsonism. BMC Neurosci. 2018;19(1):29.

11. Joshi R, Kamat JP, Mukherjee T. Free radical scavenging reactions and antioxidant activity of Embelin: Biochemical and pulse radiolytic studies. Chemico-biological Interactions. 2007;167(2):125-34.

12. Mahendran S, Badami S, Maithili V. Evaluation of antidiabetic effect of Embelin from Embelia ribes in alloxan induced diabetes in rats. Biomedicine and Preventive Nutrition. 2011;1(1):25-31.

13. Agrawal $\mathrm{S}$, Chauhan $\mathrm{S}$, Mathur R. Antifertility effects of Embelin in male rats. Andrologia. 1986;18(2):125-31.

14. Chitra M, Devi CSS, Sukumar E. Antibacterial activity of Embelin. Fitoterapia. 2003;74(4):401-3

15. Chitra M, Sukumar E, Suja V, Devi CSS. Antitumor, anti-inflammatory and analgesic property of Embelin, a plant product. Chemotherapy. 1994;40(2):109-13.

16. Mahendran S, Thippeswamy BS, Veerapur VP, Badami S. Anticonvulsant activity of Embelin isolated from Embelia ribes. Phytomedicine. 2011;18(23):186-8. 
17. Afzal M, Gupta G, Kazmi I, Rahman M, Upadhyay G, Ahmad K, et al. Evaluation of anxiolytic activity of Embelin isolated from Embelia ribes. Biomedicine and Aging Pathology. 2012;2(2):45-7.

18. Dhadde SB, Nagakannan P, Roopesh M, Kumar SA, Thippeswamy BS, Veerapur VP, et al. Effect of Embelin against 3-nitropropionic acid-induced Huntington's disease in rats. Biomedicine and Pharmacotherapy. 2016;77:528.

19. Hill CA, Alexander ML, McCullough LD, Fitch RH. Inhibition of X-linked inhibitor of apoptosis with Embelin differentially affects male versus female behavioral outcome following neonatal hypoxia-ischemia in rats. Developmental Neuroscience. 2011;33(6):494-504.

20. Poojari R. Embelin-a drug of antiquity: Shifting the paradigm towards modern medicine. Expert Opinion on Investigational Drugs. 2014;23(3):427-44.

21. Thippeswamy BS, Nagakannan P, Shivasharan BD, Mahendran S, Veerapur VP, Badami S. Protective effect of Embelin from Embelia ribes Burm. against transient global ischemia-induced brain damage in rats. Neurotoxicity Research. 2011;20(4):379.

22. Chitra M, Sukumar E, Suja V, Devi S. Antitumor, anti-inflammatory and analgesic property of Embelin, a plant product. Chemotherapy. 1994;40(2):109-13.

23. Donadio-Andréi S, Chikh K, Heuclin C, Kuczewski E, Charrié A, Gauchez AS, et al. Variability among TSH measurements can be reduced by combining a glycoengineered calibrator to epitope-defined immunoassays. European Thyroid Journal. 2017;6(1):3-11.

24. Jin YB, Choi HD, Kim BC, Pack JK, Kim N, Lee YS. Effects of simultaneous combined exposure to CDMA and WCDMA electromagnetic fields on serum hormone levels in rats. Journal of Radiation Research. 2013;54(3):430-7.

25. Misra HP, Fridovich I. The role of superoxide anion in the autoxidation of epinephrine and a simple assay for superoxide dismutase. Journal of Biological Chemistry. 1972;247(10):3170-5.

26. Benzie IF, Strain JJ. The ferric reducing ability of plasma (FRAP) as a measure of "antioxidant power": The FRAP assay. Analytical Biochemistry.1996;239(1):70-6.

27. Havelund JF, Andersen AD, Binzer M, Blaabjerg M, Heegaard NH, Stenager E, et al. Changes in kynurenine pathway metabolism in Parkinson patients with L-DOPA-induced dyskinesia. Journal of Neurochemistry. 2017;142(5):756-66.

28. Ayaz M, Sadiq A, Junaid M, Ullah F, Ovais M, Ullah I, et al. Flavonoids as prospective neuroprotectants and their therapeutic propensity in aging associated neurological disorders. Frontiers in Aging Neuroscience. 2019;11:155.

29. Amoateng P, Quansah E, Karikari TK, Asase A, Osei-Safo D, Kukuia KK, et al. Medicinal Plants Used in the Treatment of Mental and Neurological Disorders in Ghana. Evidence-Based Complementary and Alternative Medicine. 2018.

30. Xiong $\mathrm{N}$, Long $\mathrm{X}$, Xiong J, Jia M, Chen C, Huang J, et al. Mitochondrial complex I inhibitor rotenone-induced toxicity and its potential mechanisms in Parkinson's disease models. Crit Rev Toxicol. 2012;42(7):613-32.

31. Alam M, Schmidt WJ. Rotenone destroys dopaminergic neurons and induces parkinsonian symptoms in rats. Behavioural Brain Research. 2002;136(1):317-24

32. Sherer TB, Betarbet R, Testa CM, Seo BB, Richardson JR, Kim JH, et al. Mechanism of toxicity in rotenone models of Parkinson's disease. Journal of Neuroscience. 2003;23(34):10756-64.

33. Tanner CM, Kamel F, Ross GW, Hoppin JA, Goldman SM, Korell M, et al. Rotenone, paraquat and Parkinson's disease. Environmental Health Perspectives. 2011;119(6):866-72.

34. Borovac JA. Focus: The Aging Brain: Side effects of a dopamine agonist therapy for Parkinson's disease: A mini-review of clinical pharmacology. The Yale Journal of Biology and Medicine. 2016;89(1):37.

35. Nagatsu T, Sawada M. Levodopa therapy for Parkinson's disease: Past, present and future. Parkinsonism and Related Disorders. 2009;15:S3-8.

36. Rao SP, Sharma N, Kalivendi SV. Embelin averts MPTP-induced dysfunction in mitochondrial bioenergetics and biogenesis via activation of SIRT1. Biochimica et Biophysica Acta (BBA)-Bioenergetics. 2020;1861(3):148157.

37. Rodriguez-Rocha H, Garcia-Garcia A, Pickett C, Li S, Jones J, Chen H, et al. Compartmentalized oxidative stress in dopaminergic cell death induced by pesticides and complex I inhibitors: Distinct roles of superoxide anion and superoxide dismutases. Free Radic Biol Med. 2013;61:370-83.
38. Chang KH, Chen CM. The Role of Oxidative Stress in Parkinson's Disease. Antioxidants. 2020;9(7):597.

39. Boyina HK, Geethakhrishnan SL, Panuganti S, Gangarapu K, Devarakonda $\mathrm{KP}$, Bakshi V, et al. In silico and in vivo Studies on Quercetin as Potential AntiParkinson Agent. Adv Exp Med Biol. 2020;1195:1-11.

40. Liochev SI, Fridovich I. The effects of superoxide dismutase on $\mathrm{H}_{2} \mathrm{O}_{2}$ formation. Free Radical Biology and Medicine. 2007;42(10):1465-9.

41. Chinta SJ, Andersen JK. Redox imbalance in Parkinson's disease. Biochimica et Biophysica Acta (BBA)-General Subjects. 2008;1780(11):1362-7.

42. Adamczyk B, Adamczyk-Sowa M. New Insights into the Role of Oxidative Stress Mechanisms in the Pathophysiology and Treatment of Multiple Sclerosis. Oxid Med Cell Longev. 2016;2016:1973834.

43. Vinish M, Anand A, Prabhakar S. Altered oxidative stress levels in Indian Parkinson's disease patients with PARK2 mutations. Acta Biochimica Polonica. 2011;58(2):165-9.

44. Maciejczyk M, Żebrowska E, Zalewska A, Chabowski A. Redox balance, antioxidant defense and oxidative damage in the hypothalamus and cerebral cortex of rats with high fat diet-induced insulin resistance. Oxidative Medicine and Cellular Longevity. 2018.

45. Singh D, Singh R, Singh P, Gupta RS. Effects of embelin on lipid peroxidation and free radical scavenging activity against liver damage in rats. Basic Clin Pharmacol Toxicol. 2009;105(4):243-8.

46. Joshi R, Kamat JP, Mukherjee $\mathrm{T}$. Free radical scavenging reactions and antioxidant activity of embelin: Biochemical and pulse radiolytic studies. Chem Biol Interact. 2007;167(2):125-34.

47. Umehara $\mathrm{T}$, Matsuno $\mathrm{H}$, Toyoda $\mathrm{C}$, Oka $\mathrm{H}$. Thyroid hormone level is associated with motor symptoms in de novo Parkinson's disease. Journal of Neurology. 2015;262(7):1762-8.

48. Ehm G, Kim HJ, Jeon B. Hypothyroidism-induced Reversible Encephalopathy as a Cause of Aggravation of Parkinsonism and Myoclonus in Parkinson's Disease. Tremor Other Hyperkinet Mov. 2017;7:505.

49. Minár M, Valkovič $P$. Thyroid-induced worsening of parkinsonian tremor resistant to drugs and subthalamic nucleus deep brain stimulation. Case Rep Neurol Med. 2014;489275. doi: 10.1155/2014/489275.

50. Daimon CM, Chirdon P, Maudsley S, Martin B. The role of Thyrotropin Releasing Hormone in aging and neurodegenerative diseases. Am J Alzheimers Dis. 2013;1(1). doi: 10.7726/ajad.2013.1003.

51. Mohammadi S, Dolatshahi M, Rahmani F. Shedding light on thyroid hormone disorders and Parkinson disease pathology: Mechanisms and risk factors. J Endocrinol Invest. 2020. 10.1007/s40618-020-01314-5. Epub ahead of print. PMID: 32500445.

52. Tan Y, Gao L, Yin Q, Sun Z, Man X, Du Y, et al. Thyroid hormone levels and structural parameters of thyroid homeostasis are correlated with motor subtype and disease severity in euthyroid patients with Parkinson's disease. Int J Neurosci. 2020;24:1-11. doi: 10.1080/00207454.2020.1744595.

53. Rosalind D. Chapter 8 - Insecticides and Acaricides. Veterinary Toxicology for Australia and New Zealand $1^{\text {st }}$ edition, Rosalind. 2017;87-109.

54. Minár M, Valkovič $P$. Thyroid-induced worsening of parkinsonian tremor resistant to drugs and subthalamic nucleus deep brain stimulation. Case Rep Neurol Med. 2014;2014:489275. doi: 10.1155/2014/489275.

55. Munhoz RP, Teive HA, Troiano AR, Hauck PR, Leiva MH, Graff H, et al. Parkinson's disease and thyroid dysfunction. Parkinsonism and Related Disorders. 2004;10(6):381-3.

56. Linazasoro G, Blercom NV, Magariños C. Three in one: Case report supporting different origins of essential and parkinsonian tremors. Eur Neurol. 2006;55(2):108-9.

57. Suchitra K, Senthilkumar S, Mathew DH, Rajagopalan V, Jayakumar R. Studies on Parkinson's-Disease-Linked Genes, Brain Urea Levels and Histopathology in Rotenone Induced Parkinson's Disease Rat Model. World Journal of Neuroscience. 2020;10(04):216-34.

58. Kavuri S, Sivanesan S, Rajagopalan V. Oxidative Stress and Antioxidant Status in Rotenone Induced Rat Model of Parkinson's Disease. International Journal of Research in Pharmaceutical Sciences. 2020;11(1):1-5.

59. Kavuri S, Sivanesan S. Evaluation of Haematological Alterations in Intraperitoneal and Oral Rotenone Induced Parkinson's Disease Wistar Rats. International Journal of Pharmaceutical Research and Allied Sciences. 2019;8(2):1-13. 
Evaluation. International Journal of Pharmaceutical Education and Research. 2020;2(2):30-8

62. Chitra V, Manasa K, Tamilanban T, Narayanan J. Effect of Canscora decussata Extract against the Neurochemical and Behavioral Changes Induced by 1-Methyl-4-Phenyl-1, 2, 3, 6-Tetrahydropyridine in Mice. Indian J of Pharmaceutical Education and Research. 2018;52(1):87-93.

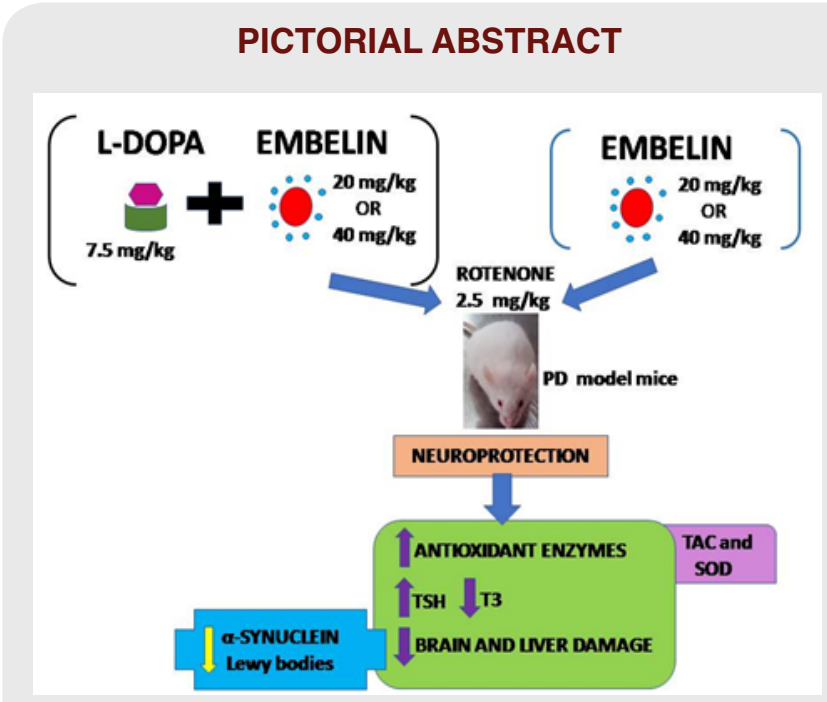 \\ SUMMARY \\ The present study evaluated the neuroprotective role of natural product embelin treated as alone and in combination with Levodopa in rotenone induced PD mice. PD was induced by administering $2.5 \mathrm{mg} / \mathrm{kg}$ of rotenone by intraperitoneal route of administration. Two doses of embelin $20 \mathrm{mg} / \mathrm{kg}$ and $40 \mathrm{mg} / \mathrm{kg}$ were tested in mice separately and the same administered in combination with Levodopa. Study was conducted for 21 days. The results of present study depicted that administration of rotenone to mice caused PD and decreased TAC and SOD levels, with increased TSH and low T3 implicating impaired anti-oxidant status, thyroid related changes accompanied by brain and liver damage. On contrast, drug treatment with a combination of embelin $(40 \mathrm{mg} / \mathrm{kg})$ and levodopa $(7.5 \mathrm{mg} / \mathrm{kg})$ to PD mice showed better neuroprotective activity than the remaining drug treatment groups. The current in vivo research showed that embelin at $40 \mathrm{mg} /$ $\mathrm{kg}$ along with half dose $(7.5 \mathrm{mg} / \mathrm{kg}$ ) of the standard $(15$ $\mathrm{mg} / \mathrm{kg}$ levodopa) therapy was effective to ameliorate many PD associated problems in mice.

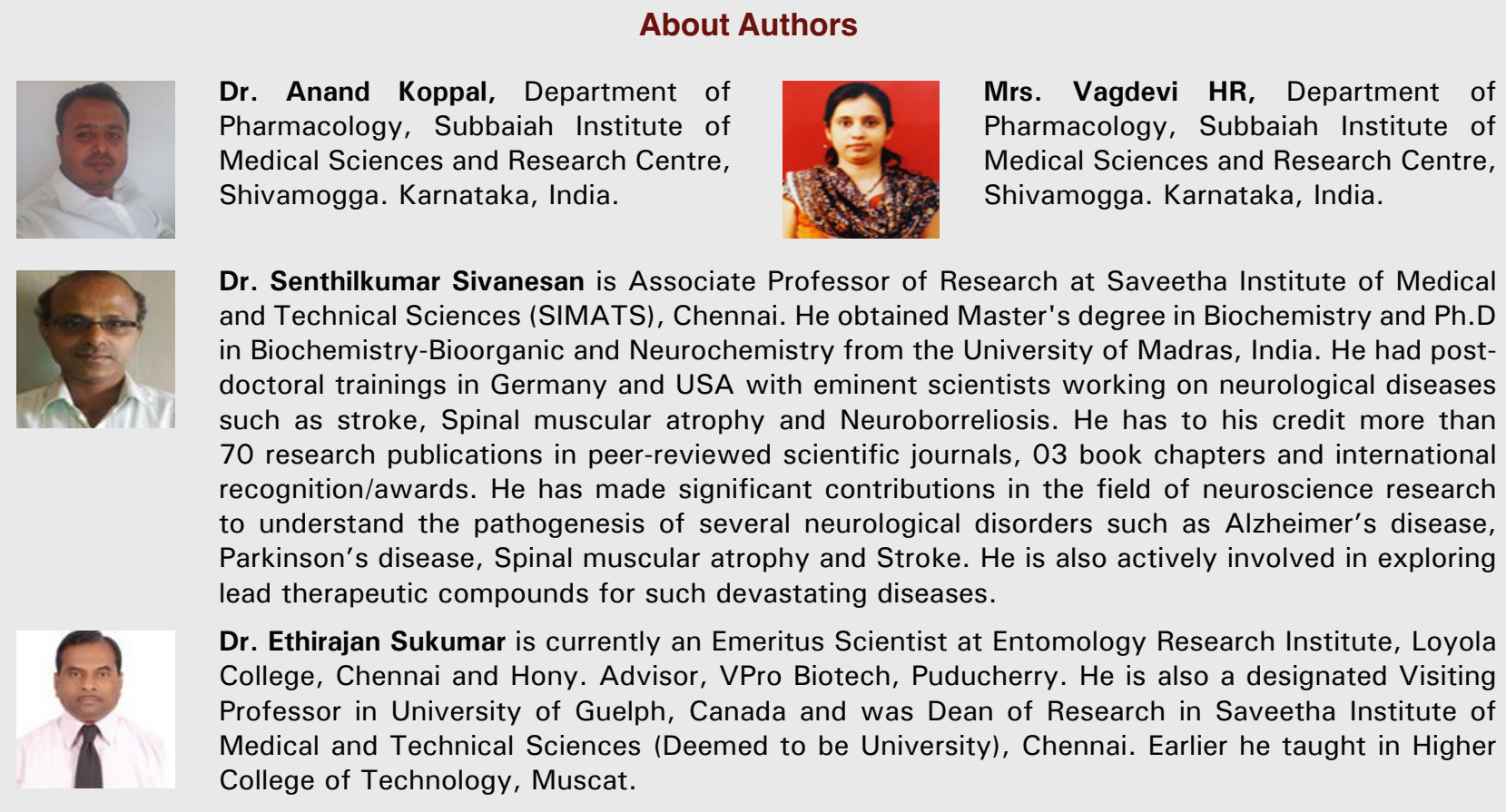


Dr. R. Vijayaraghavan is the is the Director of Research at Saveetha Institute of Medical and Technical Sciences (SIMATS), Chennai, working on drug discovery, formulation and delivery systems. Prior to this, he served in the Defence Research and Development Establishment, Gwalior as the Director and Outstanding Scientist and established inhalation toxicology facility

Cite this article: Koppal A, Sivanesan S, Vagdevi HR, Ethirajan S, Vijayaraghavan R. Embelin and Levodopa Combination Therapy Mitigates Parkinson's Disease Complications in Mice. Indian J of Pharmaceutical Education and Research. 2021;55(2s):s468-s478. 